\title{
A LINGUISTIC APPROACH TO THE DETECTION OF MINIMAL LANGUAGE DYSFUNCTION IN APHASIA
}

\author{
CLAIRE PENN, B.A. (Sp. \& H. THERAPY) (WITWATERSRAND) \\ Department of Speech Pathology and Audiology, \\ University of the Witwatersrand, Johannesburg
}

\begin{abstract}
SUMMARY
Linguistic tests, based on an expressive language sample and clinical tests of aphasia, were administered to a minimally impaired aphasic subject in an at tempt to compare their relative utility and sensitivity. Tests based on a linguistic framework were found to be far more sensitive to the crrors in the subject's language than traditional clinical tests. Specifically, the linguistic tests isolated difficulties with the processing of deep structure relations of complex sentences. Various reasons for the results are suggested and some points are made regarding the validation of theoretical constructs through aphasic language data. A suggested model for the classification, testing and therapy of aphasic disorders, based on linguistic theory, is postulated.
\end{abstract}

\section{OPSOMMING}

'n Minimaal afasie pasiënt is onderwerp aan linguistiese toctse, wat gebaseer is op 'n ekspressiewe taalmonster en kliniese toetse van afasic. Daar is gepoog om onderskeidelik die bruikbaarheid en sensitiwiteit van die toetse te vergelyk, Daar is gevind dat toetse wat op 'n linguisticse raamwerk gebaseer is, meer sensitief is t.o.v. van die foute wat in die taal van die proefpersoon voorkom, in vergelyking met die konvensionele kliniese toctse. pie linguistiese toet se het meer probleme t.o.v. dic verwerking van diep struktuurverwantskappe van gekompliscerde sinne uitgelig. Verskeie motiverings vir die resultate, sowel as aspekte betreffende die geldigmaking van teoretiese samestellings deur afatiese taalgegewens is aangevoer. 'n Voorgestelde patroon vir dic klassifikasic van afasie, wat op linguistiese teorieë gebaseer is, is gepostuleer.

During the past few years, the Theory of Generative Grammar and experiments based on this theory have done much to increase our knowledge of the structure of normal language. It has been shown that such an approach has had particularly valuable application in the testing of language capabilities. Only very recently has it been suggested that these methods may also prove useful in the area of language pathology, notably, aphasia.

The Theory of Generative Grammar proposed originally by Chomsky ${ }^{2}$ is based on the fact that the speaker of a language can potentially create and understand an unlimited number of sentences. This abstract capability is referred to as the competence of a speaker and is characterized as a system of rules which can generate an infinite number of sentences in a language and assign a structural description to each sentence. This system of rules of linguistic description consists of three main components - the syntactic, semantic and phonological components. $2,6,8,14$ 
The syntactic component which is viewed as the central device in the grammar, generates the sentences of the language, assigning to each both an underlying phrase-marker (which represents the deep structure of the sentence) and, by means of transformational rules, a derived phrase-marker (which represents the surface structure). The meaning of the sentence is derived mainly from its deep structure by means of semantic rules of interpretation and the phonetic realization (i.e. the sound) of the sentence is derived from its surface structure by means of phonological rules.

Fig. 1 provides a schematic representation of the model of generative grammar as discussed above and shows how its components are presumably related.

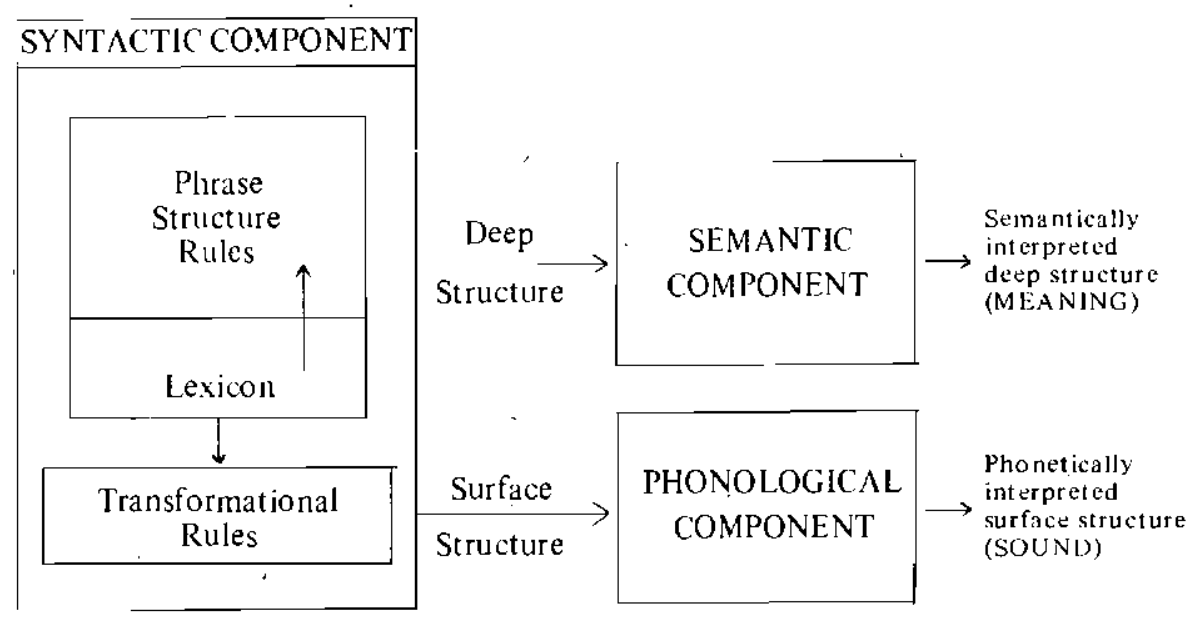

Fig. 1. The Components of a Linguistic Description (adapted from Fodor et al. ${ }^{4}$ )

Studies on the relationship between generative linguistics and aphasia are stillrather limited in number and seem to be more concerned with the validation of linguistic hypotheses than with the more practical issues of aphasia which would concern the language pathologist. For example, aphasic language data has been used to help confirm the reality of the theoretical distinction between competence and performance, the former being what the speaker-hearer actually knows about the language and the latter referring to how he actually uses the language. Some findings have indicated that in aphasia competence is intact while certain performance features are not. (See for example, the work of Schuell et al ${ }^{19}$, Taylor and $A$ nderson ${ }^{21}$, Weigl and Bierwisch ${ }^{24}$ ). Other researchers feel that aplasia has provided sufficient evidence to warrant a modification of the traditional competence-performance distinction ${ }^{26}$.

Further examples of aphasic language being used to validate linguistic hypotheses may be found in the work of linguists such as Blumstein ${ }^{1}$, Goodglass ${ }^{7}$ 
and Traill 22 who have indicated that aphasic language breakdown is systematic and logical and provides much proof for the distinctiveness of certain rules or levels of the grammar.* .

It is evident from the above discussion that while there is an increasing . amount of current research being undertaken on the more theoretical issues of linguistics, as related to aphasic language, there has been a dearth of studies on the clinical application in this area. Nevertheless, there seems to be sufficient evidence to suggest that linguistic methodology may contribute a great deal to the clinician's understanding of aphasic language, and provide, in particular, added insight into the classification, testing and therapy of aphasic disorders.

\section{Methodology can be developed within the framework of generative linguistics that not only provides insights into the nature of the langu- age deficit in aphasic patients, but is also sensitive to the severity of the aphasia deficit ... Further psycholinguistic studies should be able to develop more precise methods of assessing language deficit in aphasia.}

(Schuell et al. ${ }^{19}$ )

The rationale for the present study stems from the writer's impression that many speech therapists may not be sufficiently aware of the dynamics of language and the factors involved in its comprehension and use. A number of currently used clinical tests of aphasia are apparently insensitive to certain aspects of lariguage breakdown, particularly when this breakdown is minimal in nature. On the other hand, linguistic methods, since they are so closely related to a model which attempts to account for the entire knowledge a speaker-hearer has about his language ${ }^{2}$, could enable the clinician to test the patient's language in detail and thus assess his abilities more accurately.

The present study was thus designed to test the efficacy of linguistic methods for the detection of aphasic impairments in the hope of providing some practical evidence towards an area of cooperation which is as yet rife with theoretical facts, but limited in clinical application.

\section{METHOD}

The aim of this study is to determine the value of tests based on current lingu istic theory in discovering minimal areas of language difficulty in an aphasic subject. An attempt will be made to compare such tests with some currently popular clinical tests of aphasia in order to determine their relative utility and sensitivity.

\footnotetext{
* It is interesting to note that many of the aphasic language studies undertaken recently within a linguistic framework have served to confirm the work on normal language which has cast some doubt on the validity of some of the main constructs of Chomsky's original theory. For example, aphasic language data seems to confirm the ideas of McCawley (cited by Whitaker ${ }^{26}$ ) who suggests that syntax and semantics cannot easily be separated in reality and that semantics, not syntax is the central point in the grammar. See also, Lanham ${ }^{10}$ for a discussion of recent linguistic theory.
} 


\section{SUBJECTS}

\section{Experinental Subject}

The subject. H.J., a White male aged 57 years, was selected for the purposes of this study according to the following criteria:

Firstly, he had suffered damage to that part of the central nervous system necessary for language and had displayed evidence of a loss of linguist ic skills - two necessary criteria for aphasia, according to Tikofsky ${ }^{22}$. Secondly, he had an adequate pre-morbid acquisition of language and damage to the central nervous system was stabilized. There were no signs of dysarthria or apraxia and littlc disintegration of intellectual functioning - features which commonly confuse characterizations of aphasic language. He could express himself fairly well and make himself understood. This was an important criterion of selection since testing relied on the expressive avenue to a large extent. Finally, and most important for the purpose of this study, the subject showed aphasic impairments which were relatively subtle and would thus potentially go undetected by a therapist or doctor relying on clinical tests which are linguistically unsophisticated. His therapist in fact described him as having "totally adequ:te speech" with no receptive difficulty.

\section{Control Subjects}

4 control subjects with normal language and no history of brain damage were selccted in order to assess the suitability of the experimental tasks for nonaphasic subjects. $A$ wide age-range (from 12.73 years) was chosen specifically to ensure that the test items were appropriate for any particular age or intellectual level.

\section{THF TESTS HAPIOYED IN THE SIUDY}

In testing the language abilities of an adult who supposedly has full linguistic conpetence, the number of potential points of breakdown is extremely large. It would appear virtually impossible and certainly uneconomical to test every aspect of the linguistic system. It was therefore decided that potential areas of difficulty could best be deduced from an expressive sample. which may be considered as a starting point in a linguistic analysis.

\section{Tests for expressive speech.}

The tests employed to elicit expressive speech were:

a. Spontaneous narrative speech, where the subject was requested tó diseuss an incident of interest (adapted from Luria ${ }^{12}$ ).

b. Two sequences of pictures from the picture arrangement subtest of the Wechsler Adult Intelligence Scale where the subject was asked to describe each sequence.

c. The description of six pictures chosen from the Thematic Apperception Test - an item used successfully by many authors (e.g. Wepman and Jones ${ }^{25}$ ) to elicit a sample of expressive speech. 


\section{Linguistic Tests}

On the basis of a linguistic analysis of this expressive sample, tests were designed to assess the subject's competence with respect to a specific aspect of the grammar, namely, complex sentences. A complex sentence is one, in generative grammar terms, whose initial phrase-marker contains more than one node labelled "S" (i.e. where there is sentence embedding). An example of such a sentence is:

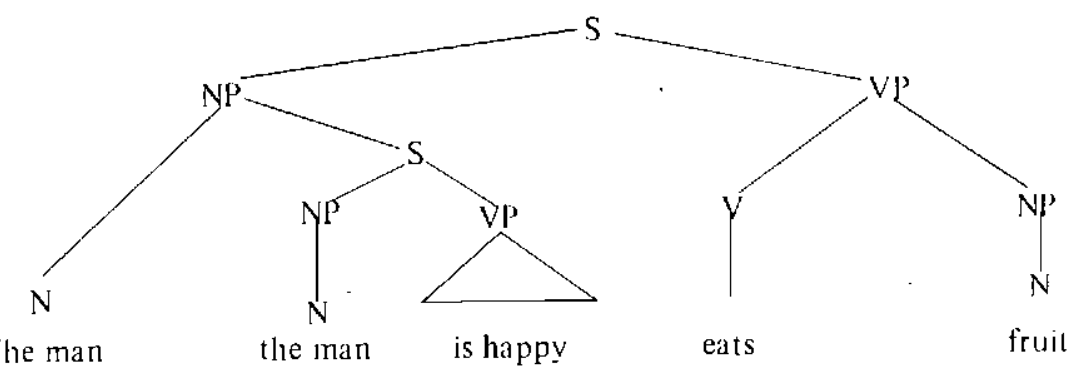

By a series of transformations, this sentence appears in the surface structure as "The man who is happy eats fruit".

The types of complex sentences tested in this study were relative sentences and complement sentences. Four types of complement sentences and 4 types of relative sentences were tested. Table I provides a brief summary of the linguistic features of each type of complex sentence. ${ }^{9}$

In addition to the 8 types of complex sentences tested, some items werc included containing more than one embedding.

Various methods were used to test the subject's competence with regard to these complex sentences.

\section{Main Tests}

Recall of Sentences. In this task, the subject was required to repeat sentences to him orally by the examiner, 25 such sentences were presented, all involving embedded sentences. This method of sentence repetition has been used by several workers as a measure of linguistic competence. (e.g. Goodglass ${ }^{7}$, Luterman and Bar ${ }^{13}$, Menyuk ${ }^{17}$ ).

Comprehension of Sentences. This method, adapted from Wright ${ }^{28}$ and Luria ${ }^{12}$ involved asking the subject questions about specific aspects of the sentence presented to him. 27 such items were compiled.

\section{Additional Tests}

Recall of Paragraphs. In this test, the subject was required to recall two paragraphs containing a large number of embedded sentences. The hypothesis made 


\section{RELATIVE SENTENCES}

(Where the embedded sentence is embedded on a NP of the matrix sentence and in some way qualifies that $\mathrm{NP}^{\text {) }}$

\begin{tabular}{|c|c|c|c|}
\hline Types & Examples & Types & Examples \\
\hline $\begin{array}{l}\text { 1. A sentence } \\
\text { embedded on a } \\
\text { subject Ni' } \\
\text { where the matrix } \\
\text { subject equals } \\
\text { the embedded } \\
\text { subject. } \\
2 . \text { A sentence } \\
\text { embedded on at } \\
\text { subject NP } \\
\text { where the matrix } \\
\text { subject does not } \\
\text { equal the em- } \\
\text { bedded subject. } \\
\text { 3. A sentence } \\
\text { embedded on an } \\
\text { object. NP where } \\
\text { the matrix object } \\
\text { equals the em- } \\
\text { bedded subject. } \\
\text { 4. A sentence } \\
\text { embedded on an } \\
\text { object NP where } \\
\text { the matrix object } \\
\text { does not equal } \\
\text { the embedded } \\
\text { subject. }\end{array}$ & $\begin{array}{l}\text { The man caught } \\
\text { the mole which } \\
\text { lad walked on } \\
\text { his lawn. }\end{array}$ & $\begin{array}{l}\text { A. Noun Phrase Com } \\
\text { (where the NP is } \\
\text { sentence so that } t \\
\text { sentence may fun } \\
\text { subject or object } \\
\text { sentence) } \\
\text { 1. Where the } \\
\text { sentence } \\
\text { acts as a } \\
\text { subject. } \\
\text { 2. Where the } \\
\text { sentence acts } \\
\text { as an object. } \\
\text { B. Verb Phrase Comy } \\
\text { (where the comple } \\
\text { is immediately do } \\
\text { constituent VP.) } \\
\text { 1. Where the ma- } \\
\text { trix sentence } \\
\text { equals the em- } \\
\text { bedded sentence. } \\
\text { 2. Where the } \\
\text { matrix sen- } \\
\text { tence does not } \\
\text { equal the em- } \\
\text { bedded sentence. }\end{array}$ & $\begin{array}{l}\text { rewplements } \\
\text { the underlying } \\
\text { nction as the } \\
\text { of the matrix } \\
\text { The fact that } \\
\text { James was stu- } \\
\text { pid. worried } \\
\text { Mary. } \\
\text { Mary denied } \\
\text { that James } \\
\text { was actually } \\
\text { stupid. } \\
\text { iplements } \\
\text { lement sentence } \\
\text { ominated by the } \\
\text { Many students } \\
\text { tend to avoid } \\
\text { hard work. } \\
\text { The fat ser- } \\
\text { geant ordered } \\
\text { the men to } \\
\text { march. }\end{array}$ \\
\hline
\end{tabular}

TABLE 1. Descriptions and examples of complex sentences. 
with respect to this test was that the subject would recall significantly fewer embedded sentences than normal control subjects.

Use of Words in a sentence. Words were given to the subject which optionally or obligatorily take an embedded sentence ${ }^{27}$ and he was asked to use them in a sentence. Where possible, he was then asked questions about his own sentence. It was hypothesized that if the subject showed general difficulty with the use of complex sentences, he would, in this task, either avoid the use of an embedded sentence altogether or show breakdown and confusion.

Performance Tests. These tests, which require a non-verbal response were included to ensure a valid interpretation of the subject's verbal responses on the preceding tests. Such tests, since they require more concrete responses (e.g. pointing) from the subject than the other tests, were inappropriate for certain types of complex sentences viz. the complement sentences, since these contain abstract relationships which cannot easily be portrayed by visual means. Thus relative sentences only were investigated in this test by means of two types of performance response. Firstly, where the subject had to carry out 9 commands all containing complex sentences using tokens from the Token Test ${ }^{3}$. Secondly, where the subject had to point to one picture out of a series of 4 which correctly portrayed the complex sentence presented to him by the Investigator. Four such items were included.

\section{Control of Performance Variables}

All test sentences were controlled for with respect to certain features of a non-linguistic nature known to affect responses on linguistic tasks. This is a very important consideration when attempting to tap the 'competence' of a subject, since it is necessary to eliminate all performance variables.

Sentence length. All test sentences were balanced for syllable length ( 10 or II syllables each) so that memory factors could be controlled for. Control sentences were administered to the subject before testing (i.e. simple sentences without embedded structures) to ascertain the number of syllables the subject could recall and comprehend without difficulty. It was presumed that if difficulty should occur in test sentences, this would be a function of sentence complexity rather than length.

Abstraction level and frequericy. In view of the fact that aphasic patients of ten encounter difficulty with words of an abstract nature and similarly have difficulty with words used infrequently ${ }^{19}$, an attempt was made to include in the test sentences fairly concrete words which appear frequently in everyday vocabulary and which were noted to be present in the subject's spontaneous speech.*

Semantic constraints. In many cases, the comprehension of a sentence is facilitated by the semantic constraints found within that sentence. ${ }^{4,12}$ i.e. words which are commonly associated together give clues as to the relation-

* Unfortunately, the feature of abstraction could not be controlled for as successfully in complement sentences as in relative sentences, since the semantic structure of the former involves more abstract at titudinal factors. 
ship between sentence constituents. To control for the possibility of the subject in this study relying on such constraints, these were as far as possible, deliberately avoided so that the subject would rely maximally on grammatical relations within the sentence. An example of such a sentence is "The man who likes squirrels, eats nuts."

\section{Clinical Tests}

The clinical tests for aphasia used in this study were selected on a pragmatic rather than a theoretical basis - that is irrespective of the theories underlying each test and the writer's bias for or against a particular theory of aphasia. Instead, the writer consulted some clinicians experienced in aphasia therapy and asked them what aphasia tests they felt to be currently most popular and useful. A further criterion for the selection of these tests was that they should be well standardized and easy to administer. The four tests selected were:

a. The Minnesota Test for the Differential Diagnosis of Aphasia (MTDDA) which is a widely-used test that has been standardized on a large aphasic population and is very comprehensive.

b. The Sklar Aphasia Scale (SAS) which is based on a modern theory of aphasia and is quick and easy to administer ${ }^{20}$.

c. The Token Test which is purported to be highly sensitive in the detection of mininal receptive aphasic disorders ${ }^{3}$.

d. Luria's tests for receptive speech which are currently very popular and test many aspects in some detail ${ }^{12}$.

Table II serves to summarize the tests administered to the experimental subject.

\begin{tabular}{|c|c|c|}
\hline Expressive Tests & Linguistic Tests & Clinical Tests \\
\hline $\begin{array}{l}\text { 1. Narrative } \\
\text { speech. }\end{array}$ & $\begin{array}{l}\text { 1. Main Tests } \\
\text { a. Recall }\end{array}$ & 1. MTDDA \\
\hline $\begin{array}{l}\text { 2. WAIS picture } \\
\text { arrangement } \\
\text { subtest. }\end{array}$ & $\begin{array}{l}\text { 2. Additional Tests } \\
\text { a. Recall of } \\
\text { paragraphs }\end{array}$ & $\begin{array}{l}\text { 2. Sklar Aphasia } \\
\text { Scale }\end{array}$ \\
\hline 3. TAT cards & $\begin{array}{l}\text { b. Pertormance } \\
\text { responses. } \\
\text { c. Use of words }\end{array}$ & 3. Token Test \\
\hline & $\begin{array}{l}\text { in a sentence. } \\
\text { 3. Control } \\
\text { sentences. }\end{array}$ & $\begin{array}{l}\text { 4. Luria's tests } \\
\text { for receptive } \\
\text { speech. }\end{array}$ \\
\hline
\end{tabular}

TABLE II. Summary of tests administered to the subject. 


\section{PROCEDURE}

H.J: was tested over a six-week period for a total of about 20 hours, during which time, the expressive, linguistic and clinical tests of aphasia were administered. Each interview was tape-recorded and transcribed immediately afterwards. While administering the clinical tests of aphasia, the investigator at tempted as much as possible to conform to the test procedures laid down by the respective test manuals. However, during administration of the linguistic tests, there was less strict application of 'standard test procedures and instructions or test items were repeated where necessary. This was done in an attempt to assess as closely as possible the subject's underlying linguistic competence by eliminating performance variables such as poor attention span and memory, known to affect test responses.

The control subjects were tested on linguistic tests only.

\section{METIOD OF ANALYSIS}

Responses on both expressive and linguistic tests were analyzed within a framework of generative linguistics. The deep structure relations of each sentence were investigated and the linguistic contexts of irrelevant linguistic features e.g. pauses were noted.

\section{RESULTS}

\section{TESTS FOR EXPRFSSIVE.SPEECH}

On a surface level, H.J's response to the expressive tests confirmed his therapist's diagnosis of "slow, but totally adequate expressive speech." Though a few word-finding difficulties were evident, very few errors of syntax or sequencing were noted and speech was fairly fluent. The only consistent feature of this expressive sample was the presence of a number of long pauses. A detailed analysis of the linguistic context of these pauses revealed a systematic breakdown in the subject's expression. It was found that in many cases, these pauses occurred in the position of a sentence boundary with in sentences i.e. in complex sentences. For example:

We caught the boat // which was taking us to Madagascar.

It was a job / / to get her onto the boat.

In phrase-marker terms, the loci of such pauses were thus:

$(\mathrm{S} 1 / /(\mathrm{S} 2))$ and

$(\mathrm{SI}(\mathrm{S} 2) / / \mathrm{SI})$

\section{LINGUISTIC TESTS}

The results of the linguistic tests confirmed the generality of H.J.'s difficulty with complex sentences.

\section{Main Tests}

Recall. In general, the recall of each type of sentence replicated expression. While a number of sentences were repeated correctly, in many cases, for both relative and complement sentences, a pause occurred in the position one would expect from an analysis of the subject's expressive speech viz. he fre- 
quently paused at the sentence boundary within a sentence. Furthermore, he frequently requested the repetition of the sentences by the investigator before he was able to recall them. With the control sentences on the other hand, (i.e. those containing no embedded constructs), the subject never requested the repetition of a sentence and, furthermore, showed no evidence of the pausing described above. Since these control sentences were matched with the test sentences for everything except sentence-embedding, it seems valid to assume that the pauses and the need for repetition noted in test sentences were thus related to the specific linguist ic features of these sentences.

Comprehension. This task proved to be a highly sensitive detector of linguistic difficulty. For all types of complex sentences, H.J. showed a consistent confusion of the deep relations within the sentence.

An example of this is:

The girl the thin boy saw was athletic.

\section{Examiner}

Was the boy athletic?

Did the girl see the boy?

Was the girl thin?

Was the girl athletic?

Did the boy see the girl?

Was the boy thin?

\section{Subject's response}

The boy was athletic.

The girl saw the boy.

The girl was thin.

The girl wasn't athletic.

The boy saw the girl.

The boy was athletic so

I think he wasn't thin.

Thus it appears that the subject is showing lack of comprehension characterized by a gross crossing of sentence boundaries. At the same time, he is showing inconsistency i.e. in the same sentence, he indicates that "the girl sees the boy" and "the boy sees the girl". Once again, H.J. repeatedly re. quested a repetition of the test items. These factors. together with the fact that questions on control sentences were consistently answered correctly and never had to be repeated. seem to provide further evidence for the hypothesis that the subject's area of difficulty lies in the processing of complex sentences.

\section{ADDITIONAL TESTS}

Results of additional tests confirmed to a large extent findings on the main tests. In the paragraph recall task, H.J. recalled only 5 out of a total of 23 embedded sentences (as opposed to an average of 16 with the normal subjects). He tended to avoid a complex sentence where possible when asked to use words in a sentence optionally taking an embedded sentence, and long pauses were evident when he was given words which obligatorily take an embedded sentence. Furthermore, he showed hesitancy and confusion on the perform. ance tasks involving the comprehension of complex sentences.

\section{CLINICAL TESTS}

The MTDDA. H.J. displayed extremely mild errors on this test. Of chief interest to the writer were his responses to the test items involving oral and aural language abilities. In the two sections involving auditory skills and speech and language skills, he made $16^{1 / 2}$ errors out of a total of 266 . The 
majority of these errors seemed to be related to an impairment in auditory retention span.

The SAS. H.J.'s score on the SAS was 5,5\% indicating "no impairment" according to the test manual.

The Token Test. H.J. made only one error out of a total of 51 items on this test. Though the authors of this test do not specify the number of errors which need to be made before a subject is considered aphasic, it appears most unlikely that a single error would indicate this.

Luria's tests for Receptive Speech. H.J. made 3 errors on Luria's tests. One of these errors which occurred in the test for "complex grammatical construc. tions" involved precisely that sentence construction which was examined in linguistic tests viz. the complex sentence, and thus ind irectly confirmed the results of these tests.

Table 111 summarizes the subject's performance on the linguistic tests and clinical tests for aplasia.

\begin{tabular}{|c|c|}
\hline LINGUISTIC TESTS & RESULTS \\
\hline 1. Recall of complex sentences. & $\begin{array}{l}\text { 1. Errors made on } 15 \text { out of } 25 \\
\text { sentences. }\end{array}$ \\
\hline $\begin{array}{l}\text { 2. Comprehension of complex } \\
\text { sentences. }\end{array}$ & $\begin{array}{l}\text { 2. Errors made on } 20 \text { out of } 27 \\
\text { sentences. }\end{array}$ \\
\hline 3. Recall of paragraphs. & $\begin{array}{l}\text { 3. } 5 \text { out of } 23 \text { complex sentences } \\
\text { recalled. }\end{array}$ \\
\hline 4. Use of words in a sentence. & 4. Evidence of delay and confusion. \\
\hline 5. Performance responses. & $\begin{array}{l}\text { 5. Errors made on } 6 \text { out of } 13 \\
\text { sentences. }\end{array}$ \\
\hline 6. Control sentences. & 6. No errors made. \\
\hline CLINICAL TESTS & RESULTS \\
\hline 1. MTDDA & $\begin{array}{l}\text { 1. "Simple aphasia" with most } \\
\text { errors in the visuo-motor } \\
\text { section. }\end{array}$ \\
\hline 2. S.A.S. & 2. "No impairment". \\
\hline 3. Token Test & $\begin{array}{l}\text { 3. } 1 \text { error made out of } 51 \\
\text { instructions. }\end{array}$ \\
\hline $\begin{array}{l}\text { 4. Luria's tests for receptive } \\
\text { speech. }\end{array}$ & 4. 3 errors made. \\
\hline
\end{tabular}

TABLE IIl. Summary of subject's responses on linguist ic tests and clinical tests for aphasia. 


\section{QUALITATIVE ANALYSIS OF THE SUBJECT'S RESPONSES}

During testing, the ease with which H.J. performed on the respective tests was noted, since it was felt that such an observation would help to confirm quantitative results. In general he appeared to find it much easier to respond to clinical tests than to linguistic tests. He completed most items in the former with relative facility and showed little fatigue. On the other hand, he showed consistent difficulty with the linguistic tests - he frequently requested rest periods and many delayed responses were noticed. His comments after testing confirmed the fact that linguistic tests were more difficult. He further reported that he would feel 'insulted' if some of the items from the clinical tests were given to him normally because of their extremely basic nature.

\section{RESPONSES OF CONTROL SUBJECTS}

The performance of the control subjects on the linguistic tests was indistinguishable from what one would expect from a normal speaker of English. Though the group was small, this was taken as evidence for the suitability of the tests for non-aphasic subjects of differing ages and intellectual abilities.

\section{DISCUSSION}

\section{LINGUISTIC TESTS VERSUS CLINICAL TESTS}

The results of this study seem to have confirmed to a large extent the hypothesis that tests based on a linguistic framework are more sensitive in detecting areas of subtle difficulty in-an aphasic patient than some currently used clinical tests.

The possible reasons for this are manifold: Firstly, one of the most striking features of the linguistic tests in comparison to the clinical tests is that the former were based on a large expressive sample of speech. A linguistic analysis of this sample provided very important guidelines for further testing. The clinical tests on the other hand, provided only limited samples of speech and were thus not adequate for the purposes of a language analysis.

The scoring methods on the clinicàl tests precluded many important features of the subject's performance. For example, some errors on the SAS were noted as being 'grammatically inappropriate' but the pass-fail system of scoring ignored the nature of these errors. This appears to be a major shortcoming of many clinical tests if one considers the chief aim of testing to be a detailed description of a patient's language abilities. ${ }^{18}$

The linguistic tests used in this study attempted to assess both the expression and reception of the subject with regard to the grammatical structure in question. This is considered to be of great importance, since only with a knowledge of both avenues, can one hope to gain a near adequate characterization of language competence. ${ }^{2,21}$ A shortcoming of the clinical tests (with the possible exception of Luria's tests) is that very rarely are the same specific language elements examined in equal depth in expression and reception. It would seem that in such tests, reception is regarded as an entity rather than as an important part of language, in fact more "rudimentary" than expressive language. 21 
Thus, though the writer is not suggesting that the clinical tests used here were totally insensitive to areas of difficulty in the subject's language, the reasons outlined above may possibly account for the fact that they were of limited value in detecting the specific areas of difficulty encountered by the subject viz, an inability to extract or retain the deep structure relations in complex sentences. It is thus not surprising that he reported little difficulty on clinical tests.

\section{A LINGUISTIC EXPLANATION OF RESULTS}

The question that remains to be answered concerns a linguistic characterization of the subject's difficulties. Is the confusion he is showing with complex sentences reflective of a basic lack of competence or can it be related to performance variables? It might be tempting to suggest, as Whitaker ${ }^{26}$ does, that since the modalities of both reception and expression are involved, the competence is impaired, but such a proposal cannot account for the variability in the subject's responses. He did not show consistent difficulty and his responses were seldom totally incorrect. Furthermore, there was evidence of paraphrasing, which according to Fodor et al. $^{4}$, is an indication of intact competence.

Clearly then, H.J.'s difficulties seem to be related to performance variables. It is less easy however, to specify the actual nature of these performance variables. One possible interfering variable, suggested by workers such as Schuell et al., ${ }^{19}$ is a decrease in retention span. According to this theory, H.J. might not be retaining the sentence long enough to recall it or to perceive its deep relations. A further possible interfering variable has been indicated by Lenneberg ${ }^{11}$ who suggests that faulty 'timing' in aphasia may lead the subject to rely on surface structure rather than deep structure clues for comprehension.

Though H.J.'s performance may indeed be related to one or both of these performance variables (or many of the others which were not controlled for and which cannot be specified) it is the writer's belief that these variables are not generalized over the entire language as Schuell et al., ${ }^{19}$ suggest. Rather, they occur within the specific linguistic context of an embedded sentence. H.J. is unable to relate portions of semantic information from one sentence to another when these sentences are in the matrix-embedded relationship. This idea is supported by the fact that he showed no difficulty with the control sentences and lends confirmation to the belief that the ". . . best explanations of performance have come from a consideration of features from the underlying grammar."2

\section{SOME THEORETICAL CONSIDERATIONS}

Some results of this study have been of interest in helping to clarify a controversial issue arising out of lingu istic theory, namely the Derivational Theory of Complexity (DTC). This theory predicts that sentence comprehension involves the diverse application of linguistic rules necessary to generate a sentence. Thus, for example, a subject would take longer to comprehend a passive sentence than an active one since the former is transformationally more complex. 
If one considers the adjective in transformational grammar terms, the length of the derivational history of a sentence-is greatly increased by the addition of an adjective before a noun. For example, the phrase "the good man" is derived from 3 basic transformations - "the man who is good" $\rightarrow$ "the man good" $\rightarrow$ "the good man". Thus in terms of the DTC, recall or comprehension of sentences containing adjectives would be poorer than recall of a simple sentence, or for that matter, one containing a relative clause only, this supposedly being the first step in an adjective transformation. The DTC would thus predict that H.J. would have great difficulty with sentences containing adjectives. This however, was found clearly not to be the case. Even in the Token Test where commands involve up to 4 adjectives per sentence (i.e. in transformational terms, 12 additional transformations), he showed no difficulty at all.

In a like manner, H.J.'s performance on test sentences where the relative pronoun or complementizer had been optionally deleted, also proved to be of interest. According to the DTC, a sentence such as "The dog the girl saw was fat." (where the relative pronoun "which" has been optionally deleted) is more complex than a sentence such as "The ball which the boy kicked was blue", (where the relative pronoun is retained). The reason for this is that an additional transformation is involved in the former; in addition deletion of the relative pronoun is felt to eliminate certain surface structure cues which normally facilitate the comprehension of underlying deep structure relations. The DTC would thus predict that H.J. would show more difficulty in sentences where these surface structure cues (i.e. the relative pronouns or complementizers) had been deleted. Aga in this was found not to be the case H.J.'s performance did not differ significantly, in either case.

It seems obvious from the above examples, that we cannot explain certain test findings in terms of the DTC and that for adjectives and the optional deletion of relative pronouns and complementizers anyway, this theory should be viewed with suspicion. This has, interestingly enough, been the general conclusion of experiments involving the language performance of normal subjects ${ }^{5}$. Thus the test data, in addition to helping to confirm that linguistic methods are useful for the study of aphasia, have also provided some insight into an area of grammar and have supported the idea that aphasia can legitimately be used as a testing-ground for linguistic theory. (cf. Marshall and Newcombe ${ }^{16}$.)

\section{CONCLUSION AND IMPLICATIONS}

On the basis of the data obtained in this study, it may be concluded that a linguistic approach to the testing of aphasia seems to be very useful for the characterization of a patient's language abilities. Furthermore it appears that such tests are sensitive to subtle and specific areas of language breakdown and thus seem superior to many clinical tests which of ten measure a general language ability rather than specific features. Test findings have also helped to provide evidence for certain issues arising out of linguistic theory.

However, there are certain shortcomings to the present study which make conclusions highly tentative and which suggest the need for a great deal of 
further research. One aphasic subject only was used, and a highly specific aspect of the grammar was investigated. Similarly, tests were limited to the oral and aural language abilities. A linguistic consideration of H.J.'s reading and writing may have helped to broaden our understanding of his problem. Finally, and probably most important, the hypothesis, tests and results of this study were considered within the framework of a theory which is not, as yet, conclusive and which is constantly changing in the light of empirical facts. As such, all conclusions and implications are only as valid as is the theory.

Nevertheless, the present study has served to highlight an approach to the classification, testing and therapy of aphasic disorders which appears to be very fruitful. The writer wishes to suggest that the following figure might help to provide a guideline to the clinician concerned with characterizing aphasic language in generative grammar terms;

\begin{tabular}{|c|c|c|c|c|}
\hline & \multicolumn{2}{|c|}{ RECEPTION } & \multicolumn{2}{|c|}{ EXPRESSION } \\
\hline & Competence & Performance & Competence & Performance \\
\hline PHONOLOGY & & & & \\
\hline SYNTAX & & & & \\
\hline SEMANTICS & & ' & & \\
\hline
\end{tabular}

Fig. 2. Proposed model for the classification and testing of aphasia

Such an outline has the following implications for diagnosis, classification and therapy:

It suggests that language breakdown may occur on a number of levels, i.e. the three levels of the grammar - phonological, syntactic and semantic - and that each level must be considered in detail when studying aphasic language; an attempt should be made to assess the subject's reception and expression with respect to these levels and, furthermore, diagnosis should aim at discovering whether the subject's problem is one of competence or performance, using linguistic methods of testing.

It has been shown that the experimental subject has a defect of a specific syntactic structure, evident in both reception and expression and related to performance features rather than a competence breakdown. Thus he may be 
fitted.into the appropriate categories of the above model. Such a characterization has helped to provide therapy cues for the subject. Since reception is basic to expression, this aspect should be worked on initially; since the defect is one of performance and not competence, therapy should involve the teaching of the successful application of the rules, rather than the rules per se. Finally, since H.J. has difficulty with a particular syntactic structure, therapy should be concerned specifically with the complex sentence - teaching him how to relate accurately features in the embedded sentence to features in the matrix sentence. ${ }^{*}$

The above model has helped to provide a highly systematic characterization of the subject's language capabilities which is essential for an adequate therapy programme. In addition, it has helped to reduce the 'confusion in terminology' which is so apparent in the field of aphasia today. ${ }^{15}$

Although, as mentioned before, there is a great need for further research both in the area of aphasic language and in the area of generative linguistics, the writer feels that cooperation between these disciplines is essential. Not only can generative linguistics provide an extremely exciting and valuable contribution to aphasic research, but it can also use the wealth of language data available from aphasia in helping to validate some of the basic theoretical constructs. It is the writer's belief that such inter-disciplinary 'cross-fertilization' will do much to increase our knowledge of aphasic, and, indeed, normal language, in the years ahead.

\section{REFERENCES}

1. Blumstein, S.E. (1973): A Phonological investigation of Aphasic speech. Mouton: The Ilague.

2. Chomsky, N. (1965): Aspects of the Theory of Syntax, M.I.T. Press, Cambridge, Massachusetts.

3. DeRenzi, E. and Vignolo, L.A. (1962): The Token Test: A sensitive test to detect receptive disturbances in Aphasics. Brain, 3, 665-678.

4. Fodor, J.A., Bever, T.G. and Garrett, M. (1968): The Developmént of Psychological models for speech recognition. M.I.T. Press, Cambridge, Massachusetts.

\footnotetext{
* It is interesting to note that the findings in the present study confirm find- ings in the literature ${ }^{5}$ regarding the value of the complex sentence as a measure of linguistic competence. The writer would suggest that even in cases who do not necessarily show obvious breakdown in complex sentences as H.J. does, the adoption of such items in assessing aphasic language (and indeed, other areas of language pathology) may prove extremely useful.
} 
5. Fodor, J.A. and Garrett, M. (1967): Some syntactic determinants of sentential complexity. Perception and Psychophysic's, 2(7), 289-296.

6. Garrett, M. (1967): Psychological theories and linguistic constructs. M.1.T. Press, Cambridge, Massachusetts.

7. Goodglass, H. (1968): Studies on the grammar of aphasics. Chap. 5 in Developments in applied psycholinguistic research. Rosenberg, $\mathrm{S}$ and Koplin, J.H. (Eds.) MacMillan, London.

8. Griffiths, P.D. (1968): A critical Examination of Competence, Unpublished Report, Dept., Linguistics, University of Edinburgh, Scotland.

9. Jacobs, R.A. and Rosenbaum, P.S. (1968): English Transformational Grammar. Blaisdell Publishing Co., London.

10. Lanham, L.W. (1973): How do we do linguistics now? A question for academic linguists in the mid.70's. Unpublished Report, Dept., Phonetics and General Linguistics, University of the Witwatersrand, Johannesburg.

11. Lenneberg, E.H. (1967): Biological Foundations of Langtage Wiley, New York.

12. Luria, A.R. (1970): Traumatic Aphasia: Its Syndromes: Psychology and Treatment. Mouton Press, The Hague.

13. Luterman, L.B. and Bar, A. (1971): The diagnostic significance of sentence repetition for language impaired children. $j$. Speech and Hearing Dis., 36(1), 29-39.

14. Lyons, J. (1971): Generative syntax. Chap 6 in New Horizons in Lingtistics, Lyons, J. (Ed), Pelican, London.

15. MacMahon, M.K.C. (1972): Modern Linguistics and Aphasia. British J. Dis. Comm., 7(1), 54-63.

16. Marshall, J.C. and Newcombe, F. (1966): Syntactic and semantic errors in paralexia. Neuropsychologia, 4, 169-176;

17. Menyuk, P. (1971): The Acquisition and Development of Language. Prentice Hall, New Jersey.

18. Osgood, C.E. and Miron, M.S. (1963): Approaches to the Study of Aphasia, U. of lllinois Press.

19. Schuell, H., Jenkins, J.J. and Jiménez.Pabón, E. (1964): Aphasia in Adults. Harper and Row, N.Y.

20. Sklar, M. (1966): Sklar Aphasia Scale Manual. W. Psychological services, California.

21. Taylor, O.L. and Anderson, C.B. (1968): Neuropsycholinguistics and language re-training. Unpublished Report, Indiana $U$.

22. Tikofsky, R.S. (1966): Language Problems in Adults. Chap. 11 in Speech Pathology. Rieber, R.W. and Brubaker, R.S. (Eds.). N. Holland Publishing Co., Amsterdam.

23. Traill, A. (1970): Transformational Grammar and the case of an Ndebele speaking aphasic. J. of the S.A. Logopedic Soc. 17, 48-66.

24. Weigl, E. and Bierwisch, M. (1970): Neuropsychology and linguistics: Topics of common research. Foundations of Language, 6, 1-18.

25. Wepman, J.M. and Jones, L.V. (1969): Five Aphasias: A commentary on aphasia as a regressive linguistic phenomenon. Chap 13 in Disorders of Communication. $\mathrm{McK}$ rioch, D. and Weinstein, E.A. (Eds.), Hafner. 
26. Whitaker, H.A. (1969): On the representation of language in the human brain. Working Papers in Phonetics 12. UCLA, Los Angeles.

27. Whitaker, H.A. (1972): Unsolicited nominalizations by aphasics: the plausibility of the lexicalist model. Linguistics, 78, 62-71.

28. Wright, P. (1972): Some observations on how people answer questions about sentences. J. Verb. Learn. Verb. Behav., 11, 188-195.

\title{
GAMPU|
}

\author{
BOOKS YOU SHOULD POSSESS
}

BROWN, R.

A FIRST LANGUAGE: THE EARLY STAGES

BAR.ADON, A., \& LEOPO LD (EDS.)

Price R13,30

Postage 35 cents.

CHILO LANGUAGE; A BOOK OF READINGS Price R12,05 Postage 35 cents.

TRAVIS, L.E. (ED.) HANDBOOK OF SPEECHPATHOLOGY\& AUDIOLOGY (REVISED)

Price R25,40 Postage 35 cents.

C. VAN RIPER

THE TREATMENT OF STUTTERING

Price R10.95 Postage 35 cents.

KATZ, J. (ED.) HANDBOOK OF CLINICAL AUDIOLOGY

Price R17,40 Postage 35 cents.

JERGER, J. (ED.) MODERN DEVELOPMENTS IN AUDIOLOGY' (REVISED)

Price R15,60 Postage 35 cents.

and other books/en ander boeke;

PHINEASHOF,

PHINEAS COURT.

BERTHASTRAAT 34 ,

34 BERTHA STREET

BRAAMFONTEIN

BRAAMFONTEIN.

JOHANNESBURG.

JOHANNE SBURG,

POSBUS 31361 .

P.O. BOX 31361 .

BRAAMFONTEIN 2017.

BRAAMFONTEIN 2017.

TEL : 724-8541

TEL: $724-8541$ 